\title{
La pandemia de la COVID-19: de la crisis sanitaria a los desafíos históricos emergentes
}

\section{COVID-19 pandemic: from sanitary crisis to historical emerging challenges}

Francisco Javier Mazeres Gaitero 1 1,a

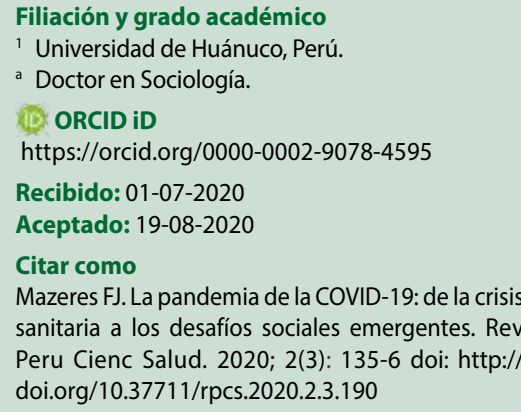

\begin{abstract}
Esperamos que haya un margen de tiempo para abordar o comenzar a abordar a fondo nuestros problemas y nuestras posibilidades en estas tierras donde se desaprovecharon tantas ocasiones propicias y donde se han perdido tantos años
\end{abstract}

(Jorge Basadre, 1931) ${ }^{(1)}$.

A pesar de haber sido uno de los primeros países de la región en decretar el estado de emergencia sanitaria y tomar medidas excepcionales para evitar su propagación, los más recientes recuentos sobre la evolución de la pandemia por la COVID-19 no dejan lugar a dudas sobre la magnitud de la tragedia a escala nacional. Perú engrosa la decena de países a nivel mundial con más contagios en términos absolutos (segundo en América Latina detrás de Brasil), además de encabezar ya la tasa de mortalidad en términos relativos ${ }^{(2)}$.

Franqueado el shock inicial, esta adversa coyuntura nos exige formular ahora -a las puertas del bicentenario-, diversos balances acerca del país que tenemos; esperando que a la catarsis sucedan la autocrítica y el propósito de enmienda. Es más, sospecho que entre las secuelas que han dejado tras de sí las discusiones iniciales, formuladas en torno a la tramposa y reduccionista dicotomía entre la vida o la economía, pueda encontrarse la de haber favorecido la expansión de la escala del sufrimiento. Pues bien, a continuación trataré de contribuir al debate público esbozando fugazmente tres aspectos que, a mi parecer, expresan sendos desafíos medulares; y lo haré, además, poniendo especial énfasis en acotar, dentro de cada uno de ellos, el papel que puede jugar la universidad frente al reto que afronta el conocimiento en todo tiempo y lugar: explicar el presente $y$, de ser posible, transformarlo.

En primera instancia parece existir un problema de percepción ya que los síntomas de la crisis sanitaria nos impiden distinguir esa otra crisis silenciosa pero civilizatoria que la explica, caracterizada por la profundización de un modelo de desarrollo que, al no poder conciliar el crecimiento económico con la equidad social y la protección ambiental, nos empuja hacia el fin de las certidumbres ${ }^{(3)}$, situándonos ante la denominada sociedad del riesgo ${ }^{(4)}$. La universidad puede jugar aquí, qué duda cabe, un rol esencial siempre que consiga reorientar la superficialidad que produce la actual fragmentación disciplinar ${ }^{(5)}$ hacia un horizonte transdisciplinar ${ }^{(6)}$, en pro de la "consiliencia" entre las diversas áreas y dimensiones del conocimiento humano (7); favoreciendo así la convergencia de los tres grandes sistemas de la vida: naturaleza, economía y sociedad.

En segundo lugar, la racionalidad monológica del homo academicus ${ }^{(8)}$, mantiene intactos los viejos tabúes de la tribu; lo que impide resolver esa relación tutelar, cuando no de asimilación o 
dominación, queel cientificismopositivistahegemónico mantiene con los otros saberes, produciendo un empobrecimiento en nuestra comprensión de la vida. Para muestra la tendencia hacia la "confiscación" del espacio público en torno a las prácticas del cuidado, por parte de "expertos" epidemiólogos, infectólogos y virólogos durante esta crisis ${ }^{(9)}$, profundamente disociadas de las prácticas culturales hibridas (10) utilizadas por el grueso de la ciudadanía. La clave, sin embargo, parece estar en encontrar una ruta dialógica para la producción de saberes, en donde las instancias de extensión universitaria pueden abanderar una voluntad genuina por estrechar los lazos con la comunidad mediante dinámicas de aprendizaje bidireccional que garanticen, asimismo, políticas de investigación sostenidas y en sintonía con el desarrollo nacional.

Por último, surge la necesidad de encontrar alternativas a la cadena de malas praxis que, durante las últimas décadas, han conducido a la precarización de la salud pública. Inicialmente a partir de un enfoque biopatocéntrico basado en el diagnóstico especializado que nos hace tecnológicamente dependientes y no ha generado el impacto deseado. A continuación, desde el punto de vista de la gestión sanitaria, hace falta invertir la pirámide de intervención sobre la base de la prevenciónyla reparación frentea la atención delas crisis recurrentes (COVID-19, dengue, malaria, tuberculosis, etc.). Finalmente, admitir que las estrategias de concentración del poder en la gestión de la crisis, al no contar con mediaciones locales, provocan una escasa respuesta de la comunidad. Por el contrario, urge construir un modelo público unificado de integración horizontal basado en un enfoque de participación social que, recuperando el espíritu de la Declaración de Almá-Atá (1978) de la OMS/OPS y UNICEF, garantice el derecho a la salud universal eintegral en el país. De nuevo aquí, las universidades son escenarios propicios para fortalecer las instancias de cogestión, empoderando a la población en el autocuidado mediante experiencias de salud comunitaria que fomenten la responsabilidad y el compromiso ciudadano, tan exiguos durante la pandemia.
En síntesis, esta crisis ha conseguido poner en evidencia la presencia de fallas de largo aliento de carácter estructural, epistemológico y político, a partir de las cuales debe ser revisado un modelo de país agotado y deficiente del que deriva un sistema de salud signado por la falta de gobernanza. El dilema que enfrentamos reside en adaptarnos y ser resilientes o atrevernos a explorar aquellas zonas de grandes desafíos históricos de donde extraer las trasformaciones hacia donde apuntan estos nuevos tiempos. Entretanto, la universidad se encuentra impelida a afrontar la transición hacia el nuevo paradigma de la complejidad ${ }^{(11)}$, recuperando una perspectiva holística y crítica sobre el mundo que podríamos sintetizar parafraseando el voluntarismo político que Jorge Basadre prescribía como particular antídoto contra la resignación nacional: problema y posibilidad.

\section{REFERENCIAS BIBLIOGRÁFICAS}

1. Basadre J. Perú, problema y posibilidad. Lima, Perú: Studium; 1987.

2. Agencia EFE [Internet] Lima: EFE [Consultado 2020 Sep 1] Disponible en https://www.efe.com/efe/america/sociedad/peru-pasa-a-ser-el-pais-con-la-mayor-tasa-de-mortalidad-del-mundo-por-covid-19/20000013-4328559

3. Prigogine I. El fin de las certidumbres. Santiago, Chile: Andrés Bello; 1997.

4. Beck U. La sociedad del riesgo: hacia una nueva modernidad. Barcelona, España: Paidós Ibérica; 2006.

5. Bunge M. Emergencia y convergencia. Novedad cualitativa y unidad del conocimiento. Barcelona, España: Gedisa; 2004.

6. Nicolescu B. La transdisciplinariedad, una nueva visión del mundo. Francia: Ediciones Du Rocher; 1998.

7. Wilson EO. Consilience: la unidad del conocimiento. Barcelona, España: Galaxia Gutenberg; 1999.

8. Bourdieu P. Homo academicus. Buenos Aires, Argentina: Siglo XXI; 2008.

9. Infobae [Internet] Argentina:TXH Medios S.A.; 2002 [Consultado 2020 Sep 3] Disponible en: https://www.infobae. com/america/mundo/2020/08/22/danilo-martuccelli-sociologo-de-la-universidad-de-paris-la-pandemia-muestra-una-tendencia-a-la-confiscacion-de-la-democracia-por-parte-de-los-expertos/

10. García-Canclini N. Culturas hibridas. Estrategias para entrar y salir de la modernidad. México D.F. México: Grijalbo; 1990.

11. Morín E. Introducción al Pensamiento Complejo. BarceIona, España: Gedisa; 1997. 